\title{
(TROPICAL REPORT) \\ EVALUATION OF THE INTRINSIC AND EXTRINSIC FRACTURE BEHAVIOR OF IRON ALUMINIDES
}

\author{
[19X-ST547C, WVU-2] \\ B.R. Cooper ${ }^{1}$ and B.S.-J. Kang ${ }^{2}$ \\ ${ }^{1}$ Physics Department \\ ${ }^{2}$ Mechanical and Aerospace Engineering Department \\ West Virginia University \\ Morgantown, WV 26506
}

\section{SUMMARY}

In this paper, we first present the status of our computational modeling study of the thermal expansion coefficient of $\mathrm{Fe}_{3} \mathrm{Al}$ over a wide range of temperature and evaluate its dependence on selected additives. This will be accomplished by applying an isobaric Monte Carlo technique. The required total energy of the sample will be computed by using a tight-binding (TB) method that allows us to significantly increase the size of the computational data base without reducing the accuracy of the calculations. The parameters of the TB Hamiltonian are fitted to reproduce the band structure obtained by our quantum mechanical full-potential LMTO calculations. The combination of the three methods mentioned above creates an effective approach to the computation of the physical properties of the transition-metal aluminides and it can be extended to alloys with more than two components. At present, we are using a simplified approach for a first-round of results; and as a test of the simplified approach, have obtained excellent agreement with experiment for aluminum.

Our previous experimental results showed that, because of their smaller grain size, FA-187 and FA-189 are extrinsically more susceptible to environmental embrittlement than FA-186 under low strain loading condition. To further investigate the grain boundary size effect as related to the susceptibility of hydrogen embrittlement, we conducted comparative finite element modeling simulations of initial intergranular fracture of two iron aluminides (FA186 and FA189) due to hydrogen embrittlement. Sequentially coupled stress and mass diffusion analyses are carried out to determine crack-tip stress state and the extent of hydrogen diffusion at the crack tip region, and a proper failure criteria is then adopted to simulate the intergranular fracture. Good qualitative agreement between the modeling predictions and experimental results is observed.

\section{CALCULATION OF THE THERMAL EXPANSION COEFFICIENT OF Fe $3 \mathrm{AI}$}

The transition-metal aluminides are an important class of structural materials because of their high melting temperature and exceptional strength retention at high 
temperature. Therefore, it is essential to learn as much as possible about the thermal properties of these materials. Our goal is to calculate the thermal expansion coefficient of $\mathrm{Fe}_{3} \mathrm{Al}$. This problem is challenging for the following reasons. First is the need to calculate the wide spectrum of the vibrational frequencies that are responsible for the effect. Second is the fact that the thermal expansion is a consequence of anharmonic terms in the interatomic potential. This requires both considering a large size supercell, of at least one hundred atoms, and keeping a sufficient accuracy during the calculations. This makes it not feasible to solve the problem by any direct $a b$ initio calculations. Tight-binding method is a good alternative in this case.

The procedure of tight-binding parameterization consists of evaluating the energy matrix elements, solving the corresponding secular equation, and obtaining the energy bands throughout the Brullouin zone. The parameters are found by fitting energy bands and total energy at different deformations into the results obtained by ab initio LMTO calculations. To fit such a very large amount of data, one needs to increase the number of parameters. In our case this is done by introducing non-orthogonal basis functions. We completed the first step and obtained the parameters that reproduce with a good accuracy the uniform expansion of $\mathrm{Fe}_{3} \mathrm{Al}$.

While trying to complete the parameterization for the structure of $\mathrm{Fe}_{3} \mathrm{Al}$ under other kind of deformations which yield symmetry breaking, we decided to test our methodology and calculated the thermal expansion coefficient of pure Aluminum. To make our calculation less time consuming, we applied the local harmonic approximation $(\mathrm{LCH})$. In this approximation the atoms are treated as harmonic oscillators seated at the lattice sites and the anharmonicity of their motion is included in the first order in the volume dependence of the vibriational frequencies. These assumptions allow us to derive the analytical expression for the thermal expansion coefficient. Knowing the total energy of the system the vibrational frequencies were found from eigenvalues of dynamical matrices. For Aluminum we obtained the linear volume dependence of the frequencies, and good agreement between experimental results and calculated values of the thermal expansion coefficient just near and above the Debye temperature. For temperatures higher than that, the anharmonicity becomes important and LCH can no longer be applied. However, application of Monte Carlo technique will increase the temperature 
range of the calculations. We will test this for Aluminum, and then proceed to the thermal expansion calculations for binary alloys and particularly of $\mathrm{Fe}_{3} \mathrm{Al}$. Our final goal in this study will be to perform these calculations over a wide range of temperature and assess the dependence of the thermal expansion coefficient of $\mathrm{Fe}_{3} \mathrm{Al}$ on the additives such as rhenium, niobium and molybdenum.

\section{COMPUTATIONAL MODELING OF HYDROGEN EMBRITTLEMENT OF IRON ALUMINIDES}

\section{(a) Motivation and Summary of Experimental Results Relevant To The Computational Analysis}

We have conducted comparative crack growth tests of three iron aluminides subjected to constant tensile loading in air, oxygen or water environment. Moiré interferometry was applied to obtain full-field crack tip displacements, from which crack extension, crack growth rate, crack-tip strain fields, and stress intensity factor were evaluated [1]. In this paper, we first summarized the experimental results that are relevant to the computational modeling analysis. Table 1 shows the alloy composition of FA-186, FA-187 and FA-189 as well as specimen geometry. Figure 5 shows typical microstructure of these alloys and the grain sizes are estimated to be $193 \mu \mathrm{m}, 72 \mu \mathrm{m}$ and $75 \mu \mathrm{m}$, respectively. Table 2 shows the test matrix. As shown, a total of sixteen comparative crack growth tests under air, oxygen or water environment were conducted. Figure 4 and 5 show representative moiré fringe patterns of alloys FA-186 and FA-189 tested in air. Also, shown in the figures are sequences of maximum principal strain distributions ahead of the crack-tip with crack growth. The Maximum principal strain distributions shown in Figures 4 and 5 correlated well with actual fracture paths. For alloy FA-186 tested in air or oxygen condition, multiple cracks were formed as soon as the initial crack started to grow (e.g. Figure 4). The extension of these multiple microcracks formed an expanding damage zone, which grew slowly leading to the final catastrophic failure. This feature of extensive multiple microcracking was not found in alloys FA-187 and FA-189; instead, clear single crack growth pattern was observed (e.g. Figure 5). Test results in Table 2 also showed that with the same applied stress intensity 
factor, specimens tested in oxygen lasted 3 to 9 times longer than those tested in air, indicating the effect of moisture embrittlement for all three iron aluminides.

Figure 6 shows failure characteristics of the tested alloys in air. The fractured surface can be roughly divided into three areas corresponding to the change of failure mode. It is interested to note that, due to stress-assisted hydrogen embrittlement at the crack tip region, all the three tested specimens showed failure initiated with some amount of intergranular fracture (i.e. area 1 in Figure 6).

For alloys FA-187 and FA-189, initial crack growth always started with intergranular mode then shifted to mixed intergranular/transgranular cleavage mode and finally to transgranular failure. As the moisture content is increased in the test environment (i.e. from oxygen to air to water), we observe an increased intergranular failure pattern in area 2. For ternary alloy FA-186, except for the sample tested in water which showed substantial intergranular mode in areas 1 and 2, transgranular cleavage is the dominate failure mode. However, the sample tested in air had a very short intergranular failure initiation and then quickly changed to multiple microcracks ahead of the notch tip leading to transgranular cleavage failure.

Overall, our test results indicate that among the three alloys, the ternary alloy FA186 has the best fracture resistance, highest fracture toughness and least sensitivity to hydrogen embrittlement (Table 2).

The purpose of adding small amount of boron in FA-189 was to improve the grain boundary cohesive strength such that intergranular failure can be minimized. However, with microalloying of $\mathrm{B}$ and/or Zr, FA-187 and FA-189 have much smaller grains (Figure 3), thus, intrinsically FA-187 and FA-189 should have higher fracture toughness than that of FA-186. However, as indicated by the above experimental results, because of their smaller grain size, FA-187 and FA-189 are extrinsically more susceptible to environmental embrittlement than FA-186 under low strain loading condition. Thus, to further investigate the effect of grain boundary morphology (e.g. size effect) as related to the susceptibility of hydrogen embrittlement, we carried out comparative finite element modeling simulations of initial intergranular fracture of two iron aluminides (Faf-186 and FA-189) subjected to stress-assisted hydrogen embrittlement. The objective of the numerical modeling analyses is to correlate with the experimental results as well as to 
further validate our assertion that grain boundary morphology plays an important role on the extrinsic fracture behavior of iron aluminides in the presence of hydrogen embrittlement.

\section{(b) Computational Modeling Simulations of Initial Intergranular Fracture of Iron Aluminides}

Sequentially coupled finite element modeling of hydrogen diffusion and crack tip stress/strain analyses are carried out to simulate the initial intergranular failure mode of FA-186 and FA-189 due to hydrogen embrittlement. It should be noted that the computational modeling analysis presented here is qualitative in nature. No attempt has been made in this analysis to include the study of hydrogen transport kinetics such as incubation time period, kinetics of degradation, and the critical hydrogen concentration build-up before fracture. A brief description of the hydrogen diffusion model used in the finite element analysis is first described.

\section{Hydrogen Diffusion Model}

We follow the suggestion by Johnson [2] that hydrogen embrittlement is controlled by the diffusion of hydrogen into the crack tip region and is influenced by hydrostatic stress state. Mass diffusion is often described by Fick's law and, in this research, the extended fick's law described by Sofronis and McMeeking [3] is used.

$$
J=-D\left(\frac{\partial C}{\partial x}+S K_{P} \frac{\partial p}{\partial x}\right)
$$

where $J$ is the flux concentration, $D$ is diffusivity, $K p$ is the pressure stress factor, and $p=-\operatorname{trace}(\sigma) / 3$ where $\sigma$ is the normal stresses

The normalized concentration, $\Phi$, presented by Liu [4] has the form

$$
\Phi=\Phi_{0} \exp \left(-\frac{V_{H} p}{R\left(\theta-\theta^{z}\right)}\right)
$$

where $\Phi_{0}$ is the normalized concentration obtained in the unstressed state, and

$$
\Phi=\frac{C}{S}
$$


where $\mathrm{C}$ is the mass concentration of the hydrogen gas and $\mathrm{S}$ is the solubility in the base material. A diatomic gas that dissociates during diffusion can be described by the Sievart's law [3]

$$
C=S \otimes P^{1 / 2}
$$

where $\mathrm{P}$ is the partial pressure of the hydrogen gas.

Stress assisted -diffusion is specified by defining the pressure stress factor, $\mathrm{K}_{\mathrm{p}}$

$$
K_{P}=\frac{V_{H} \Phi}{R\left(\theta-\theta^{z}\right)} \quad \mathrm{mmN}^{-1 / 2}
$$

where $\mathrm{R}=8.31432 \mathrm{~J} / \mathrm{molK}$ is the universal gas constant, $\mathrm{V}_{\mathrm{H}}=2.0 \times 10^{3} \mathrm{~mm}^{3} / \mathrm{mol}$ is the partial molar volume of hydrogen in iron-based metals and $\Phi$ is the normalized concentration.

Finally, the following material values are selected for the computational calculations [3]

Diffusivity:

$D=2.1 \times 10^{-7} \mathrm{~m}^{2} / \mathrm{s} \times \exp \left(-\frac{6.88 \mathrm{KJ} / \mathrm{mol}}{R T}\right)$

Solubility:

$S=1.989 \times 10^{26} \sqrt{P} \times \exp \left(\frac{-28.8 K J / m o l}{R T}\right)$

Where $\mathrm{S}$ is atoms of hydrogen per $\mathrm{m}^{3}$ of iron (under normal condition of pressure and temperature)

Elastic Modulus: $\quad \mathrm{E}=1.41 \mathrm{E}+5 \mathrm{MPa}$ (matrix), $0.56 \mathrm{MPa}$ (grain boundary, FA-186), and $0.98 \mathrm{MPa}$ (grain boundary, FA-189)

Poisson's ratio: $\quad v=0.29$

\section{Steps of Simulating Intergranular Failure Due To Hydrogen Embrittlement}

In the simulating sequence, the crack is initially subjected to a mode-I loading, and hydrogen concentration (as described by the Sievart's law, Eq. (5)) is calculated. Here the transport of hydrogen (via normal interstitial lattice diffusiojn or dislocation transport [4]) is influenced by the crack tip hydrostatic stress state, as governed by Eqs. (1) and (2). It is 
assumed that material degradation will occur at the stress-assisted hydrogen concentration region. Accordingly, the material property (Young's modulus in this analysis) is reduced both at the matrix and grain boundary region by the following formula:

$\begin{array}{lc}\text { Normalized oncentration ratio } & \% \text { of reduction of Young's modulus } \\ 1 \text { to } 3 & 20 \% \\ 3 \text { to } 6 & 30 \% \\ 6 \text { to } 10 & 40 \% \\ 10 \text { to } 15 & 50 \%\end{array}$

Finite element stress analysis is then carried out to determine the updated crack tip stress/strain state, and, based on the maximum principal strain failure criterion, the possibility of intergranular cracking is evaluated and proper boundary conditions in the crack-tip submodel region are then adjusted. From the experimental results (Figures 4 and 5), we chose $0.7 \%$ strain as the failure strain in the simulation run.

Figure 7 shows the finite element mesh layout. As shown, due to symmetry of loading, only half of the specimen size is analyzed. The mesh shown on the left side of Figure 7 is referred as the global model which has a total of 1,744 elements. Near the crack tip region, two submodels are designed to represent qualitatively the grain size of FA-186 and FA-189, respectively. As shown in Figure 7, the size of hexagon shown in the submodel for FA-186 (upper right corner of Figure 7) represents typical grain size of $193 \mu \mathrm{m}$ and the submodel contains a total of 8,448 elements. The hexagon shown in the submodel for FA-189 (lower right corner of Figure 7) represents typical grain size of 75 $\mu \mathrm{m}$ and the submodel contains a total of 22,528 elements. Note that grain boundary is also properly represented in the submodel with assumed grain boundary thickness of 1.5 $\mu \mathrm{m}$. The computational modeling analyses were carried out using the commercial general purpose finite element code $\mathrm{ABAQUS}^{\mathrm{TM}}$ coupled with the hydrogen diffusion model (Eqs (1) to (5)). Typically, for each finite element stress analysis, the CPU time is 0.5 hours and, for each finite element hydrogen diffusion calculation, the CPU time is about 0.4 hours.

\section{Results and Discussions}

Figure 8 shows near crack tip hydrogen diffusion zone and maximum principal strain distribution of FA-186 at step one under applied stress intensity factor of 17.36 
$\mathrm{MPa} \sqrt{ } \mathrm{m}$. As shown, the results indicate comparatively small maximum principal strain distribution at crack-tip region (all are much below 0.7\%) and thus no crack growth is predicted. However, if the applied stress intensity is increased to $36.9 \mathrm{MPa} \sqrt{\mathrm{m}}$, a much larger and wider hydrogen diffusion zone and maximum principal strain distribution are noted, as shown in Figure 9, step 1. By selecting $0.7 \%$ as the failure strain, the relatively high crack-tip maximum principal strains are sufficient to promote initial intergranular crack growth, as indicated in the subsequent plots shown in Figure 9. If a lower value of failure strain is selected (say $0.5 \%$ ), multiple microcracks can be initiated, as indicated in the maximum principal strain distribution, step 1 of Figure 9, and eventually will lead to an expanding damage zone, which was observed in the experimental results (Table 2, Figures 4 and 6). The above assessment may be justified with the assumption that, comparing to FA-189, the ternary alloy FA-186 has a weaker grain boundary cohesive strength.

Figure 10 shows simulation results of FA-189 under applied stress intensity factor of 17.36 MPa $\sqrt{ } \mathrm{m}$ up to step 5. As shown, smaller hydrogen diffusion zone and maximum principal strain distribution are noted. However, the crack-tip strain field is sufficient to initiate continuous intergranular crack growth. This prediction is in agreement with our test results of FA-189 (Table 2 and Figures 5 and 6).

\section{SUMMARY}

We first present the status of our computational modeling study of the thermal expansion coefficient of $\mathrm{Fe}_{3} \mathrm{Al}$ over a wide range of temperature and evaluate its dependence on selected additives. The combination of the methods mentioned creates an effective approach to the computation of the physical properties of the transition-metal aluminides and it can be extended to alloys with more than two components. At present, we are using a simplified approach for a first-round of results; and as a test of the simplified approach, have obtained excellent agreement with experiment for aluminum.

Our previous experimental results showed that, because of their smaller grain size, FA-187 and FA-189 are extrinsically more susceptible to environmental embrittlement than FA-186 under low strain loading condition. Thus, to further investigate the effect of grain boundary morphology (e.g. size effect) as related to the 
susceptibility of hydrogen embrittlement, we carried out comparative finite element modeling simulations of initial intergranular fracture of two iron aluminides (FA-186 and FA-189) subjected to stress-assisted hydrogen embrittlement. Sequentially coupled stress and mass diffusion analyses are carried out to determine crack-tip stress state and the extent of hydrogen diffusion at the crack tip region, and a proper failure criteria is then adopted to simulate the intergranular fracture. Good qualitative correlation between the modeling predictions and experimental results is noted, which further validates our assertion that grain boundary morphology plays an important role on the extrinsic fracture behavior of iron aluminides in the presence of hydrogen embrittlement.

\section{ACKNOWLEDGMENTS}

This research is supported by the Office of Fossil Energy, AR\&TD Materials Program, U.S. Department of Energy, under contract no. SUB-19X-ST547C with Lockheed Martin Energy Systems, Inc. Technical assistance from Dr. C.T. Liu from ORNL is greatly appreciated.

\section{REFERENCES}

1. B.S.-J. Kang and B. Cooper, "Thermal Expansion Modeling and Fracture Behavior of Iron Aluminides," Proceedings of the Thirteenth Fossil Energy Materials Conference, Knoxville, May 1999.

2. Johnson, H. H., "Hydrogen Embrittlement and Stress Corrosion Cracking" (proc.Troiano Festschrift Symposium, Case Western Reserve University, June 1-3, 1980), p. 3 (edited by R. Gibala and R. F. Hehemann ), ASM, Ohio, 1984.

3. P.Sofronis,R.M.McMeeking, "Numerical Analysis of Hydrogen Transport Near a Blunting Crack Tip," Journal of Mechanics and Physics of Solids,Vol. 37,No.3,pp. 317-350,1989.

4. Liu, H. W., "Stress-Corrosion Cracking and the Interaction Between Crack-Tip Stress Field and Solute Atoms," Transactions of the ASME: Journal of Basic Engineering, vol. 92, pp. 633-638,1970. 


\section{Vibrational Frequencies versus Volume}

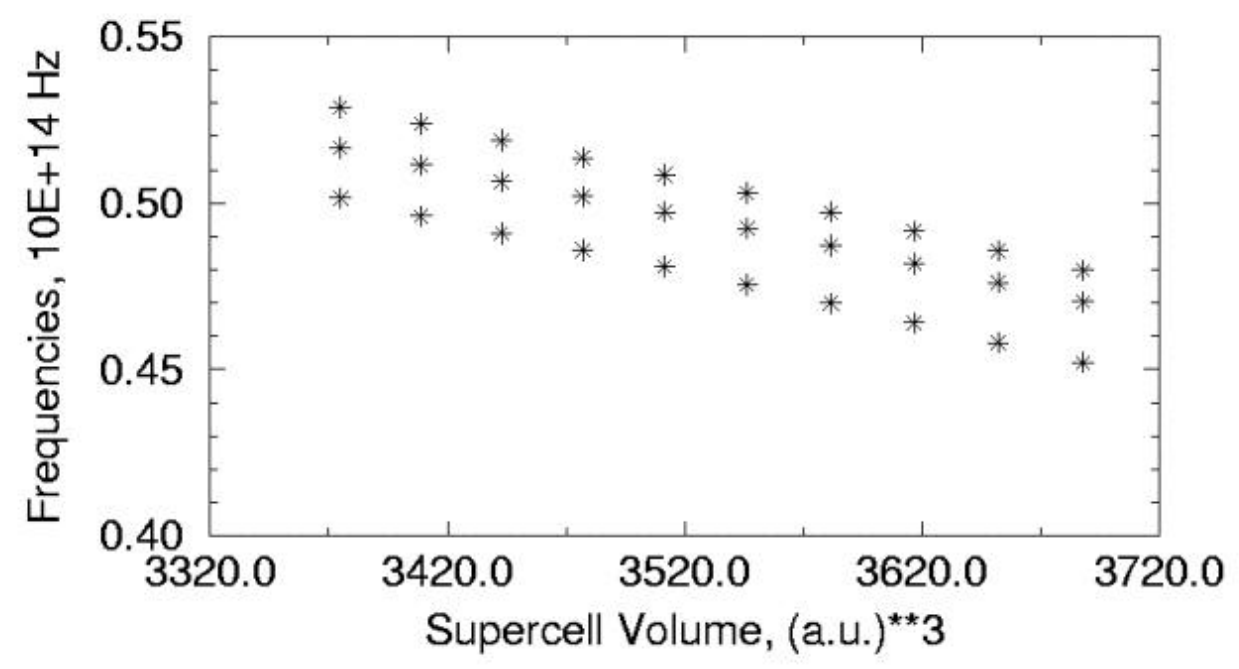

Fig. 1 Calculated vibrational frequencies of aluminum for use in thermal expansion calculations.

Thermal Expansion of Aluminum

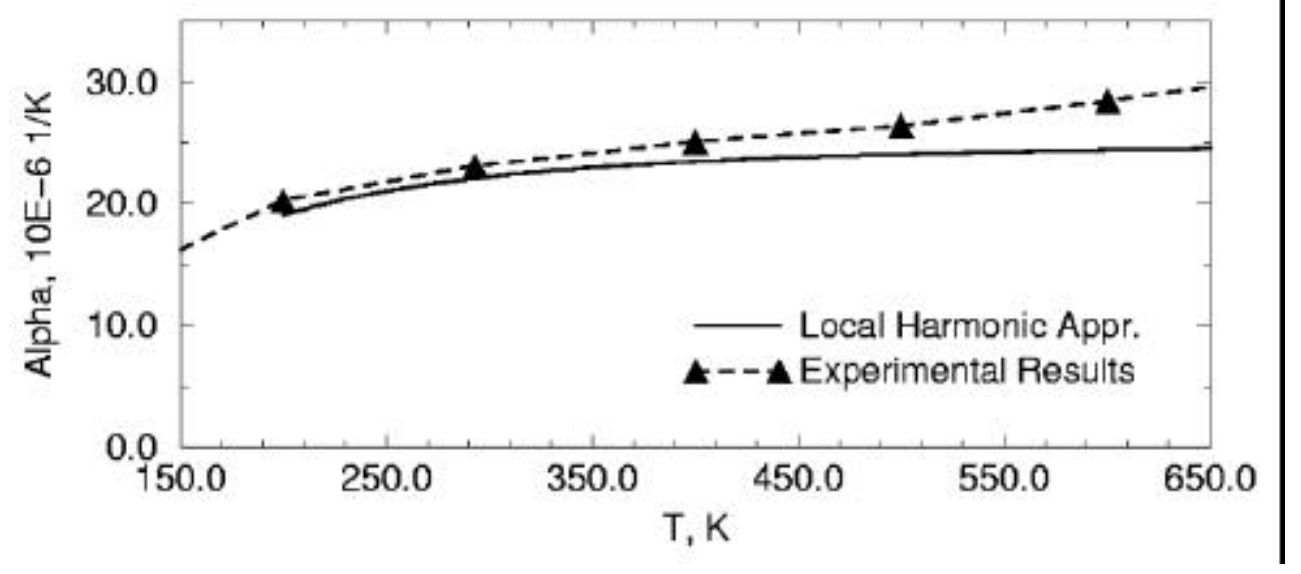

Fig. 2 Modeling of thermal expansion of aluminum by local harmonic approximation (LHA). 
Table 1 Materials

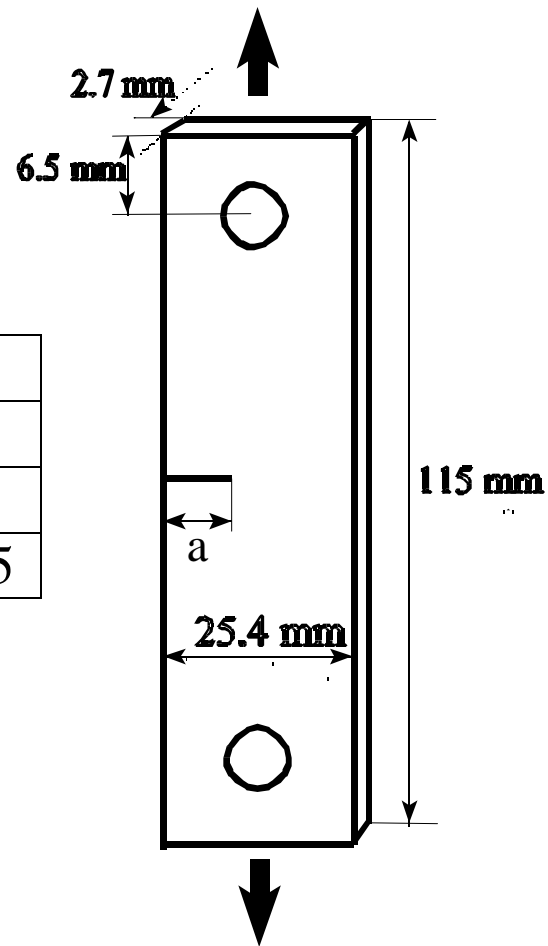

Table 2 Test Matrix

\begin{tabular}{|c|c|c|c|c|c|c|}
\hline $\begin{array}{c}\text { Iron } \\
\text { Aluminide }\end{array}$ & Specimen & $\begin{array}{l}\text { Structure } \\
\text { Condition }\end{array}$ & Initial Crack & Environment & $\begin{array}{c}\text { Initial K } \\
M P a \sqrt{m}\end{array}$ & Lasting Time \\
\hline & $86-1$ & $\mathrm{~B} 2$ & $\mathrm{FP}$ & Air & 36.9 & $7 \mathrm{~min}$ \\
\hline & $86-5$ & B2 & FP & Dry Oxygen & 36.8 & $21 \mathrm{~min}$ \\
\hline \multirow[t]{5}{*}{ FA-186 } & $86-10$ & $\mathrm{DO}_{3}$ & EDM & Air & $\begin{array}{c}25 \\
28.3\end{array}$ & $\begin{array}{c}94 \min ^{\mathrm{c}} \\
1 \mathrm{~min}\end{array}$ \\
\hline & $86-9$ & $\mathrm{DO}_{3}$ & EDM & Dry Oxygen & $\begin{array}{c}25 \\
28.7\end{array}$ & $\begin{array}{c}19 \mathrm{hr}^{\mathrm{d}} \\
21 \mathrm{~min}\end{array}$ \\
\hline & 86-w1 & $\mathrm{DO}_{3}$ & EDM & Water & $\begin{array}{l}13.35 \\
22.12\end{array}$ & $\begin{array}{c}2 \mathrm{hr}^{\mathrm{d}} \\
8 \text { second }\end{array}$ \\
\hline & $87-1$ & B2 & EDM & Air & 25 & $3.5 \mathrm{~min}$ \\
\hline & $87-5$ & B2 & EDM & Dry Oxygen & 25 & $15 \mathrm{~min}$ \\
\hline \multirow[t]{5}{*}{ FA-187 } & $87-8$ & $\mathrm{DO}_{3}$ & EDM & Air & 25 & $2 \mathrm{~min}$ \\
\hline & $87-7$ & $\mathrm{DO}_{3}$ & EDM & Dry Oxygen & 25 & $18 \mathrm{~min}$ \\
\hline & 87-w1 & $\mathrm{DO}_{3}$ & EDM & Water & 15.43 & 46 second \\
\hline & $89-2$ & $\mathrm{~B} 2$ & EDM & Air & 17.36 & $7 \mathrm{~min}$ \\
\hline & $89-1$ & $\mathrm{~B} 2$ & EDM & Dry Oxygen & 17.36 & $20 \mathrm{~min}$ \\
\hline \multirow[t]{4}{*}{ FA-189 } & $89-7$ & $\mathrm{DO}_{3}$ & EDM & Air & 17.36 & $3 \mathrm{~min}$ \\
\hline & $89-6$ & $\mathrm{DO}_{3}$ & EDM & Dry Oxygen & 17.36 & $12 \mathrm{~min}$ \\
\hline & 89-w1 & $\mathrm{DO}_{3}$ & EDM & Water & 13.1 & 60 second \\
\hline & 89-w2 & $\mathrm{DO}_{3}$ & EDM & Water & 20.76 & 8 second \\
\hline
\end{tabular}

All tests were conducted at room temperature;

b FP: Fatigue Pre-cracked; EDM: Electron-Discharge Machining;

c Slow crack growth;

d Almost no crack growth. 

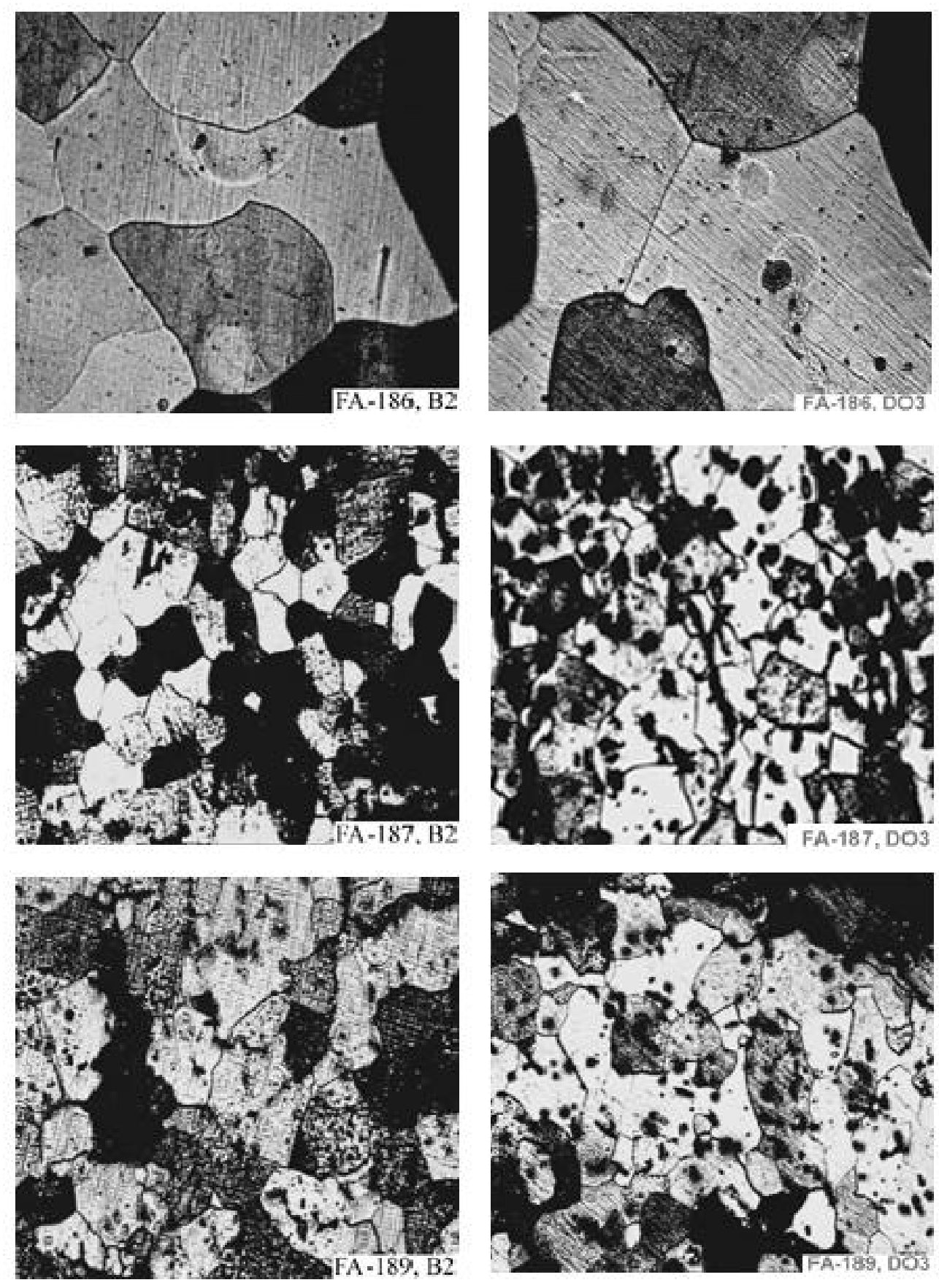

Fig. 3 Microstructure of FA-186, FA-187, and FA-189. 


\section{FA-186, Room Temp, Air}
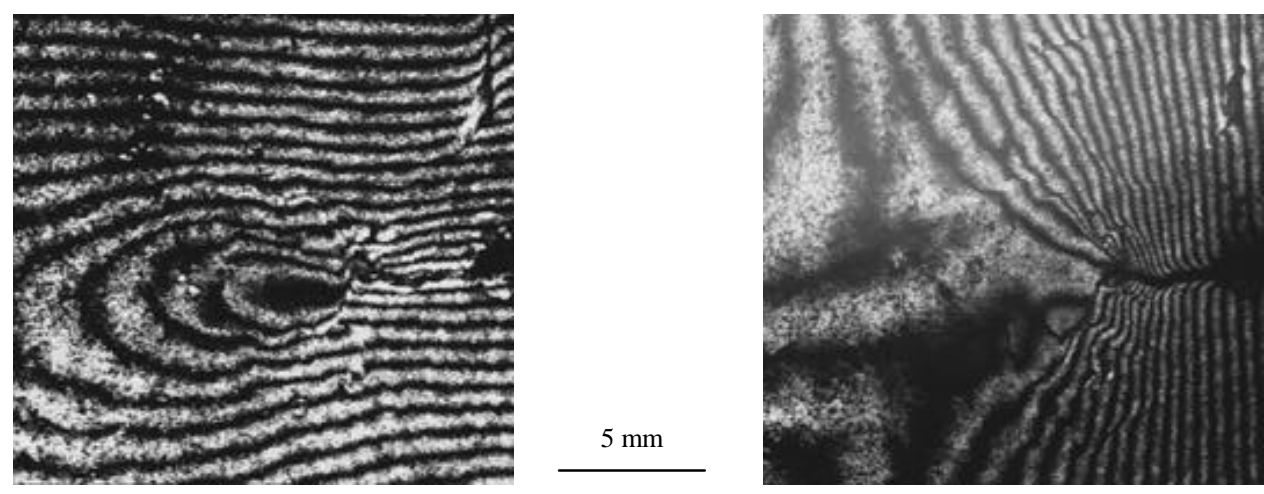

(The original moiré fringe pattern)

$\mathrm{K}=36.9 \mathrm{MPa} \sqrt{m}$ $\mathrm{t}=0$ min
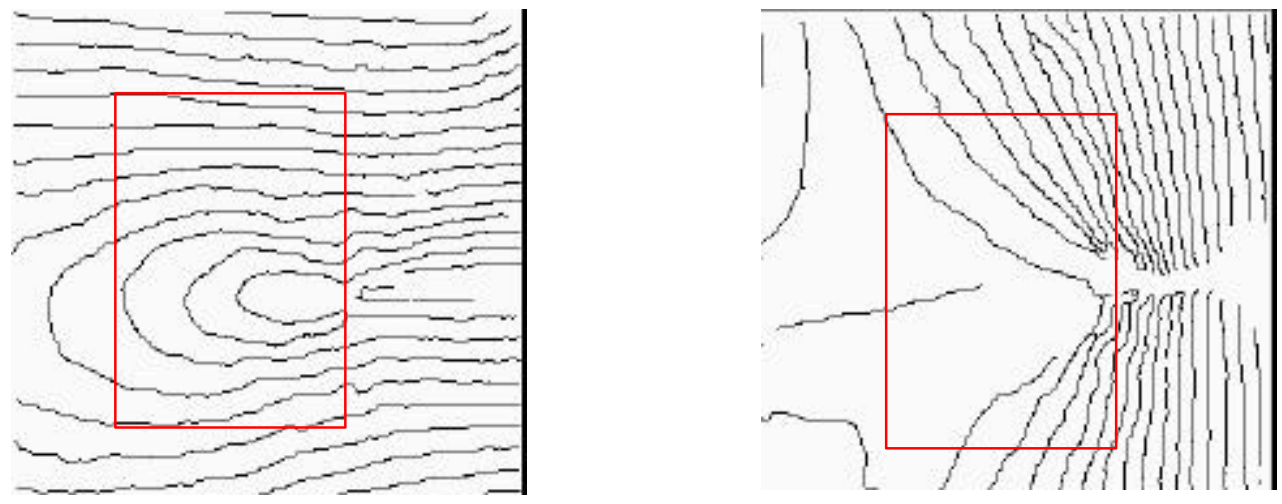

(after digital image processing)
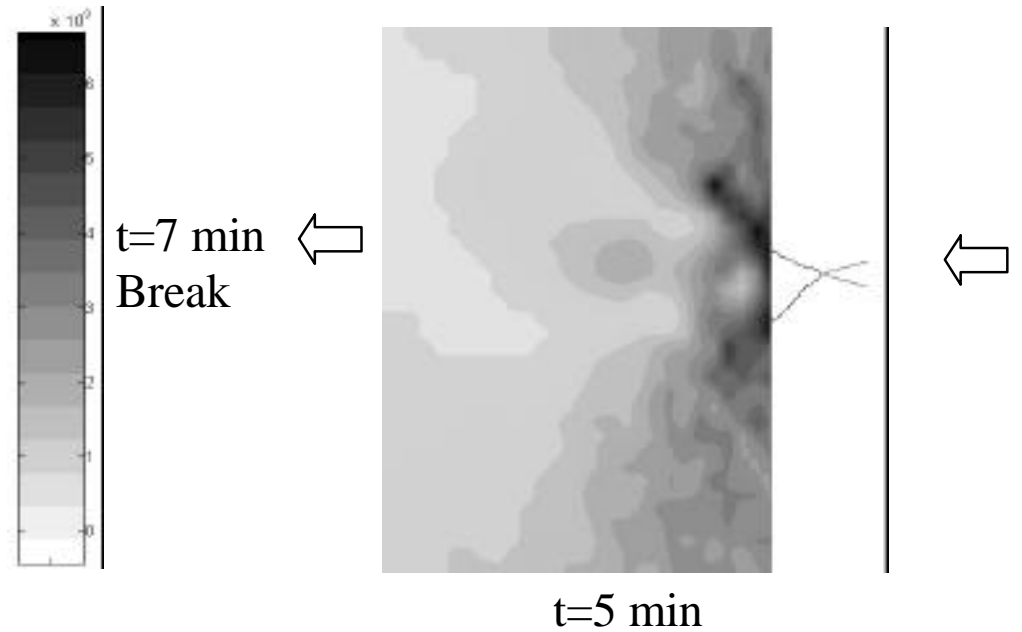

$=7 \min$

Break

Fig. 4 Maximum principal strain distribution ahead of crack tip. FA-186 SENT specimen, room temp, air. 


\section{FA-189, Room Temp, Air}

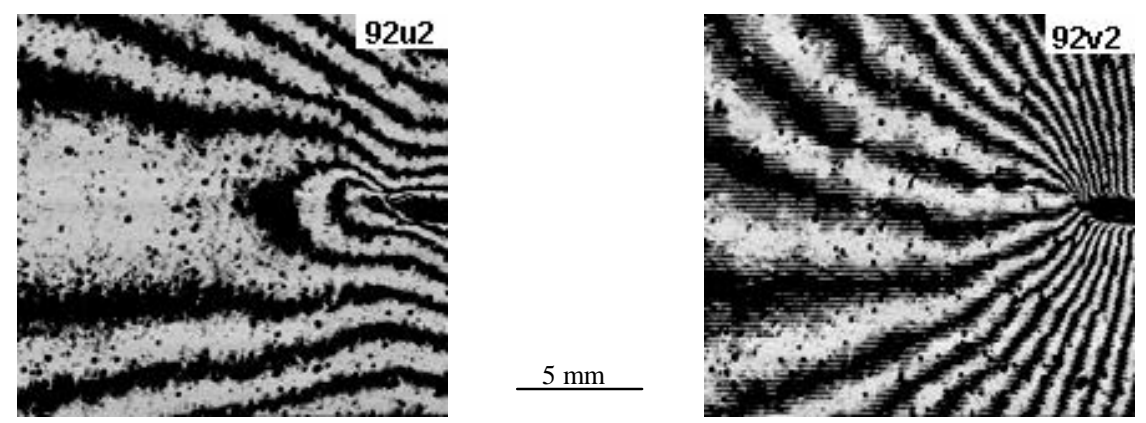

(original moiré fringe pattern)
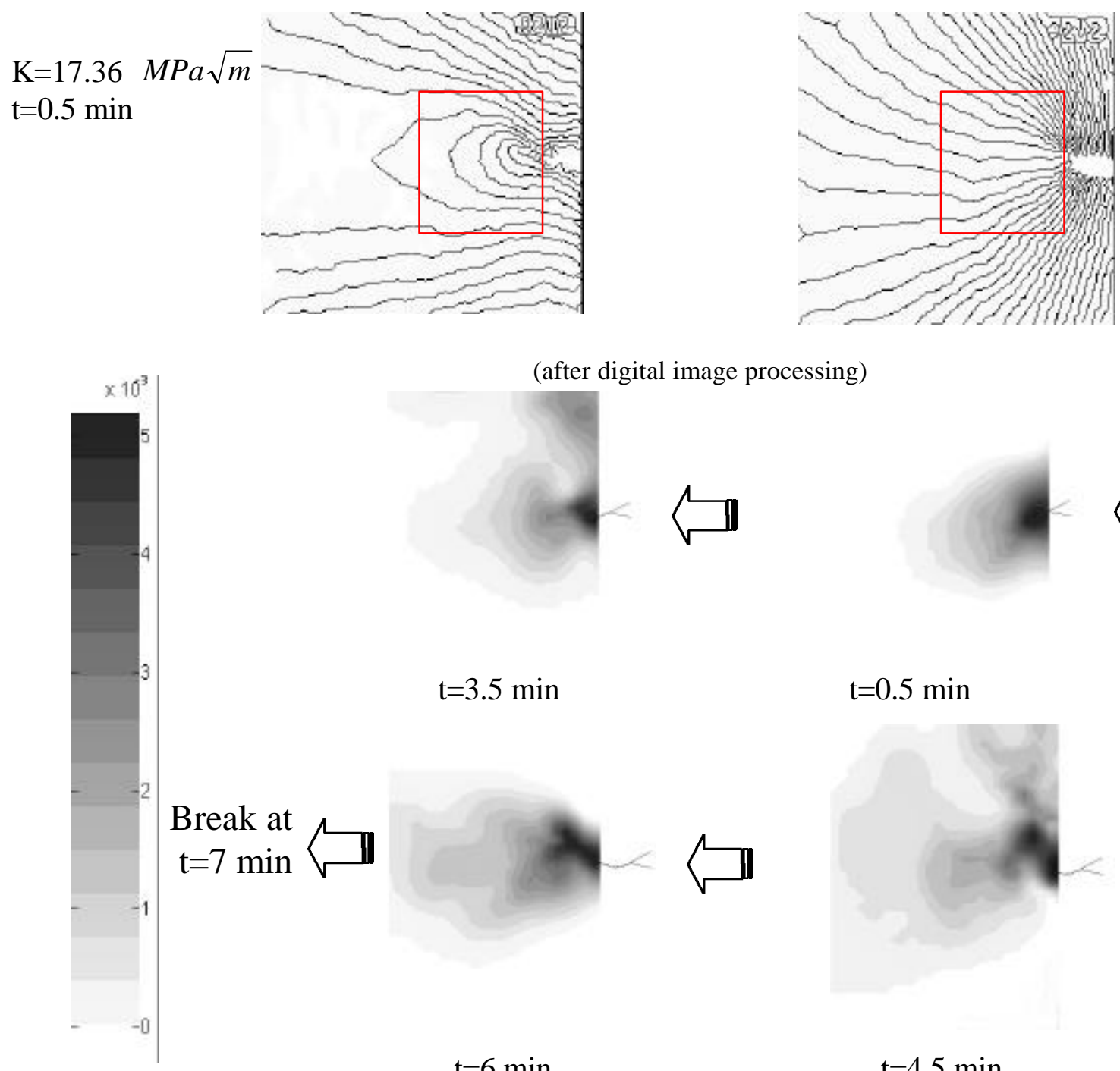

(after digital image processing)

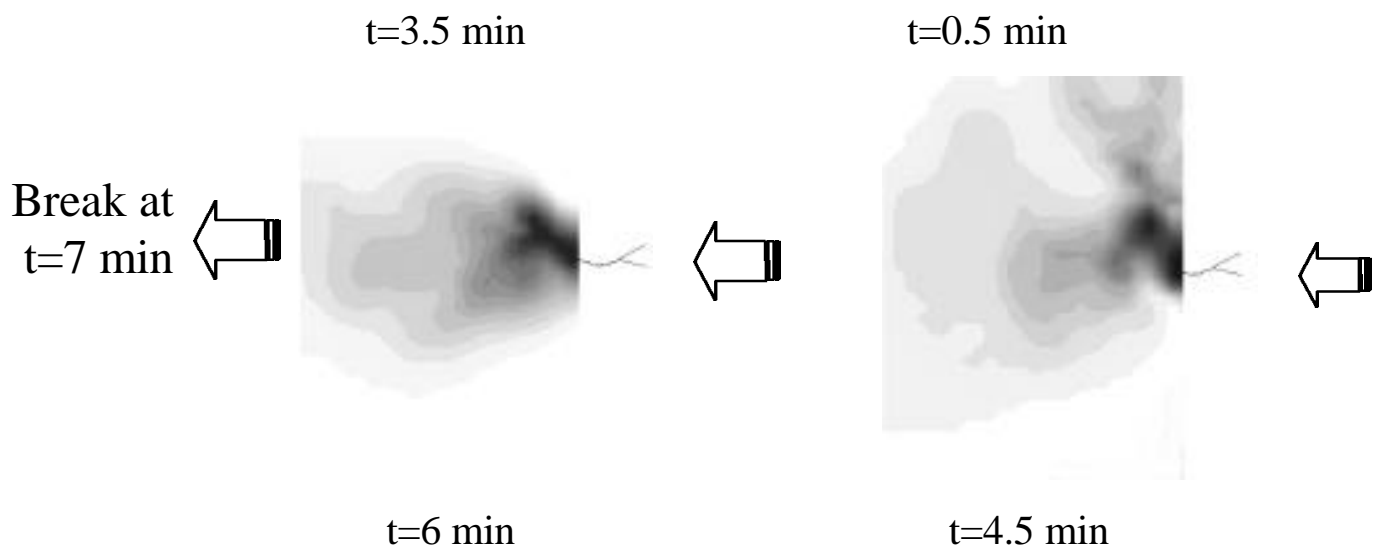

Fig. 5 Maximum principal strain distribution ahead of crack tip,

FA-189 SENT specimen, room temp, air. 


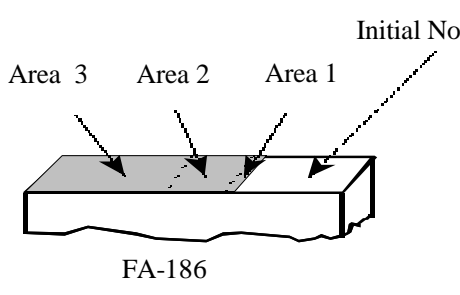

Area 1

FA-186

FA-187

FA-188

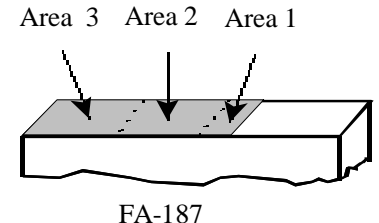

Area 2
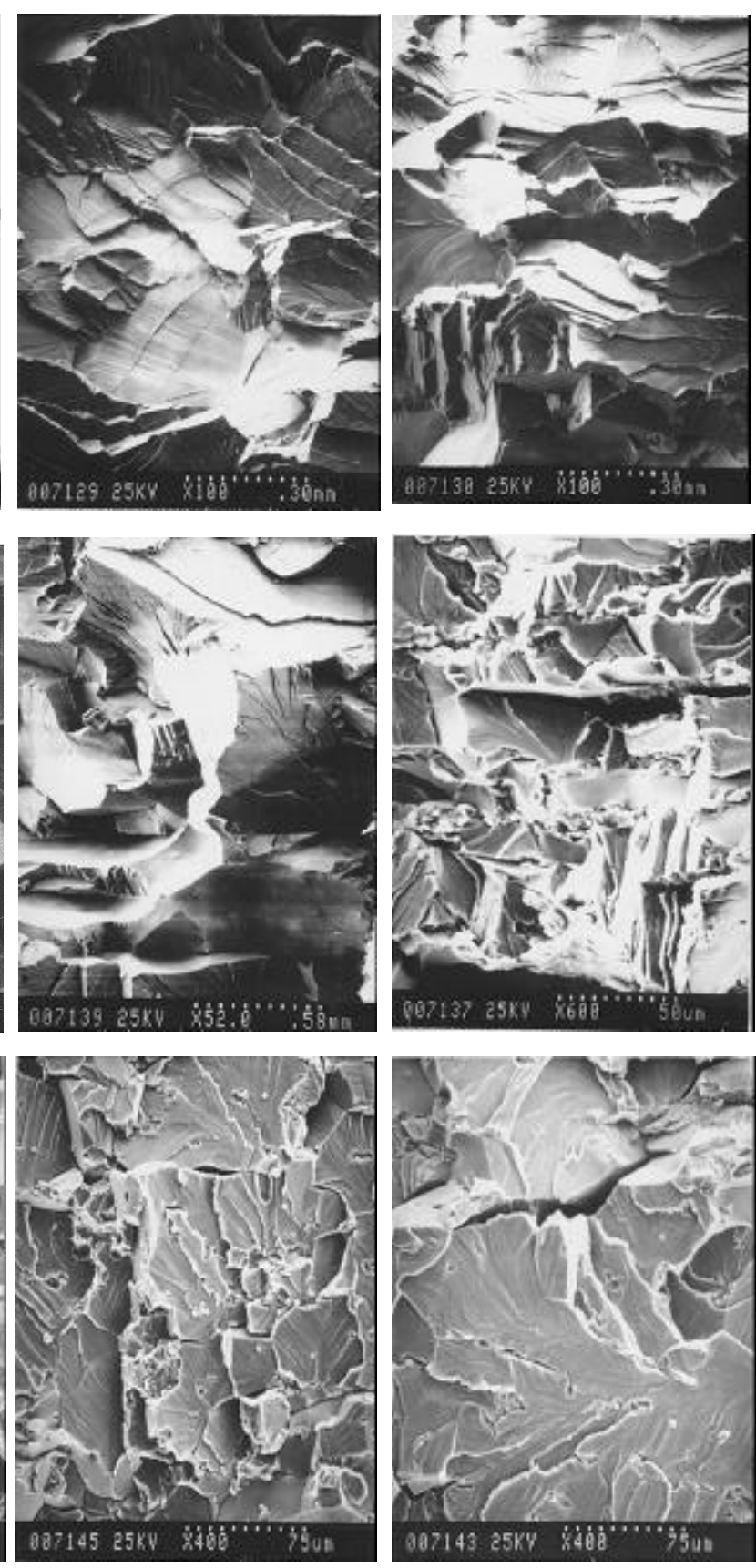

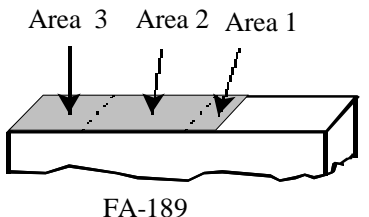

Area 3
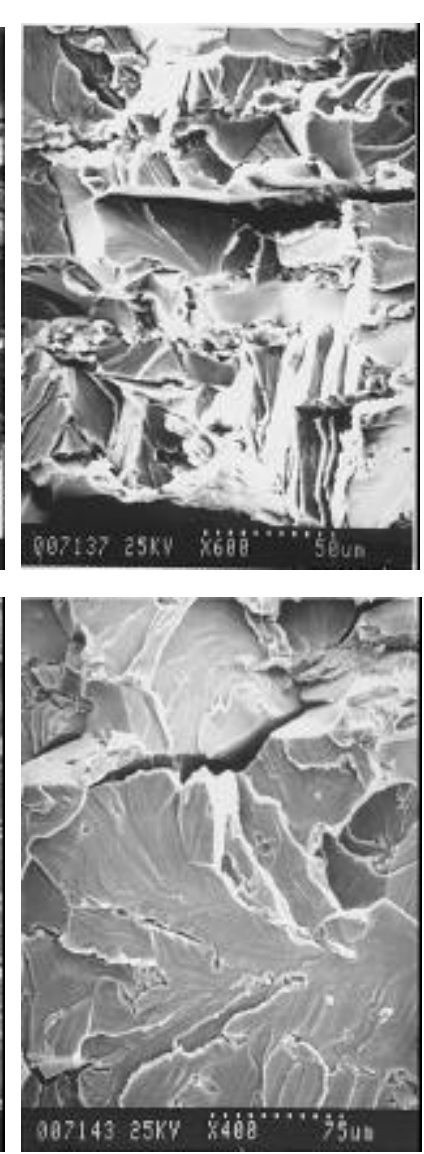
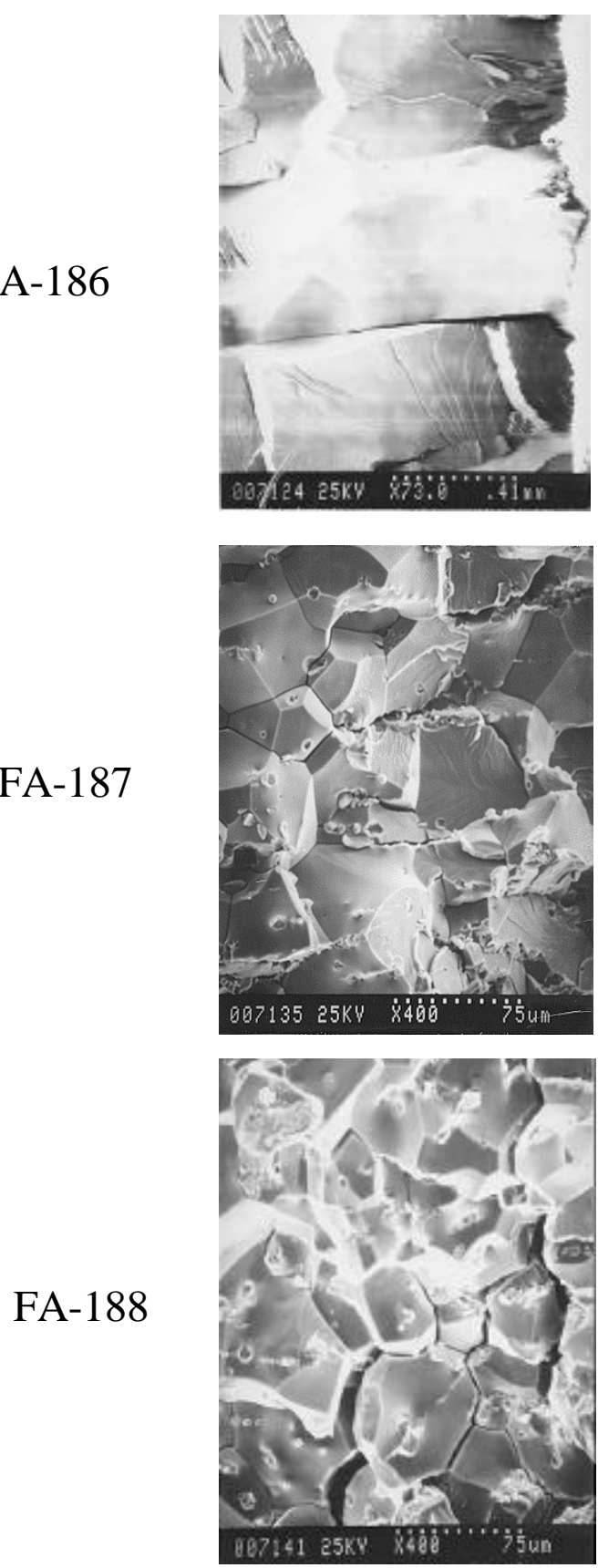

Fig. 6 Representative fractographies for FA-186, FA-187 and FA-189 in Air. 


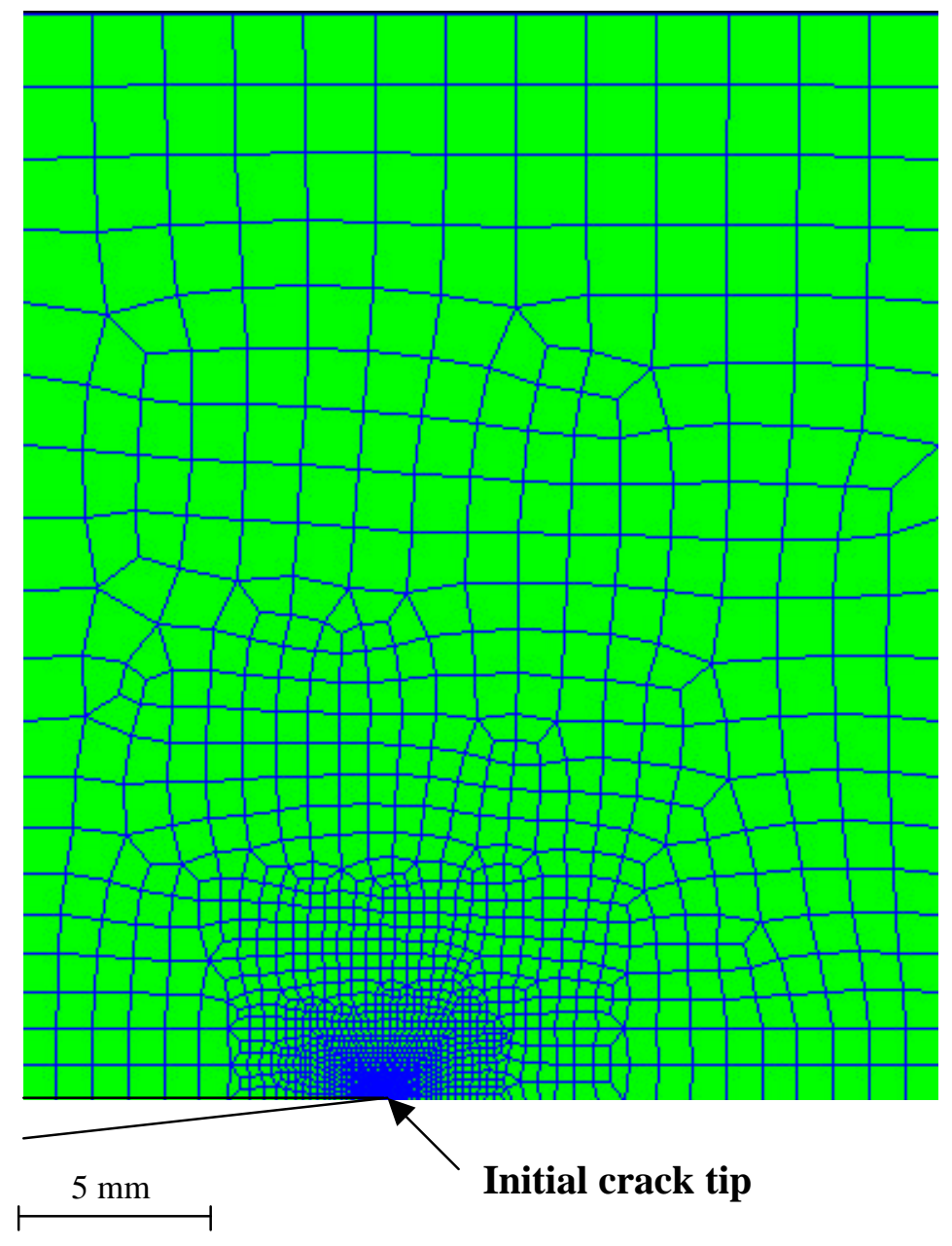

Fig. 7 Finite Element Mesh Layout.

FA $186, K_{I}=17.36 \mathrm{MPa} \sqrt{ } \mathrm{m}$

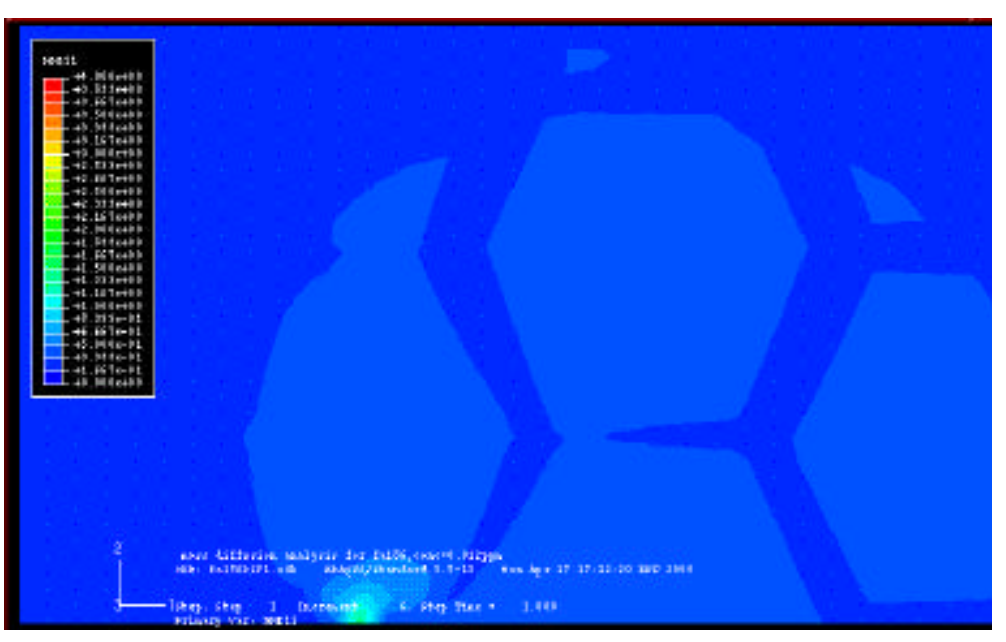

Hydrogen diffusion zone, step 1

$0.2 \mathrm{~mm}$

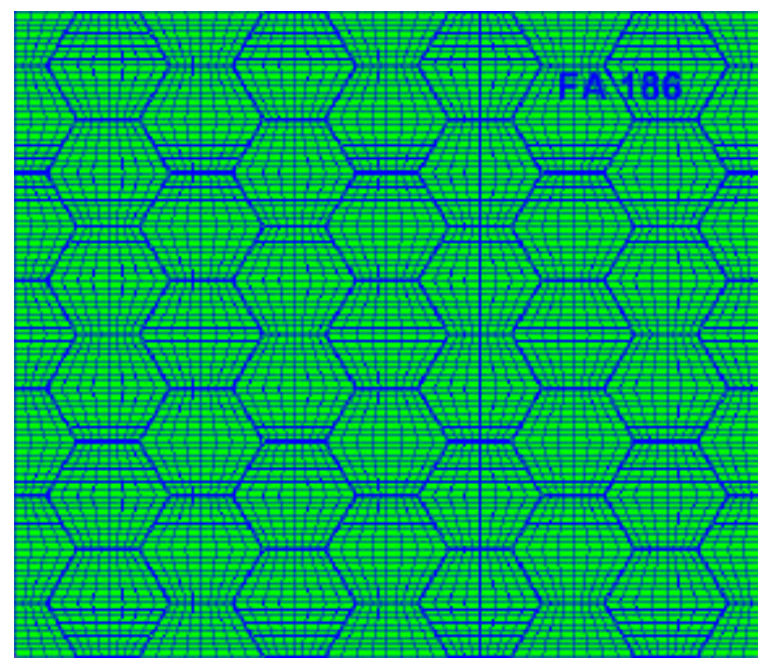

$0.2 \mathrm{~mm}$

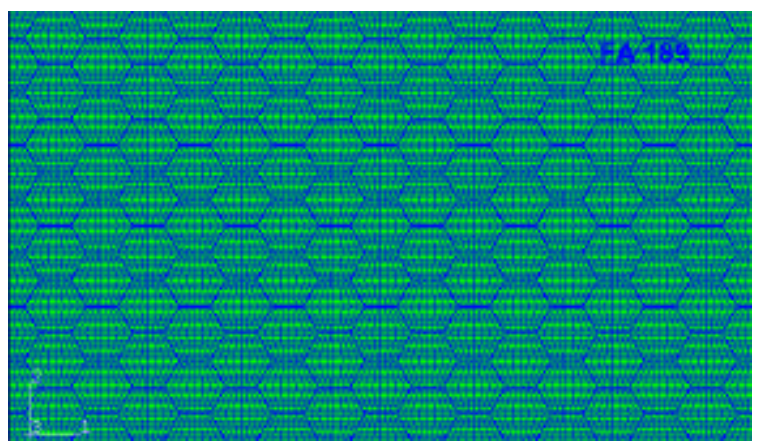

Fine mesh at crack tip region
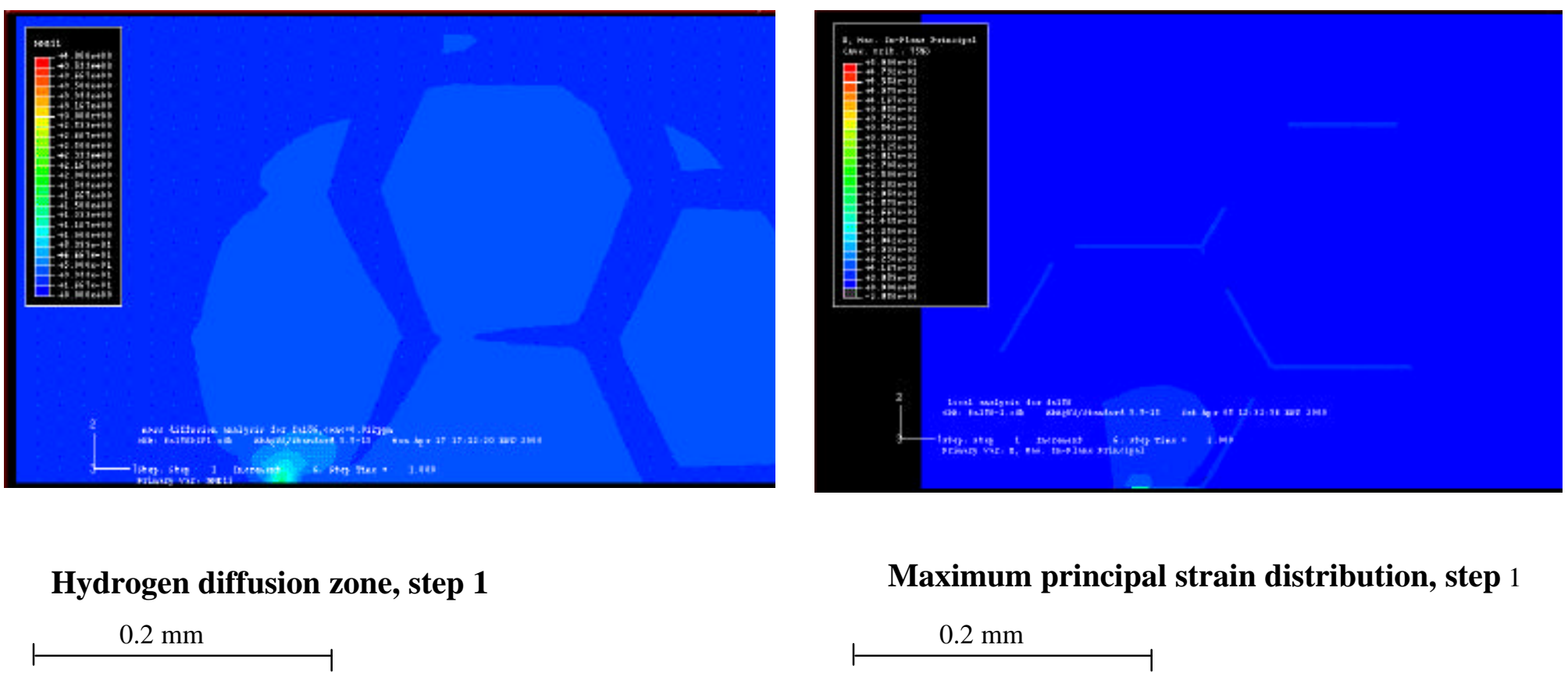

Maximum principal strain distribution, step 1

$\longmapsto$

Fig. 8 Near Crack Tip Hydrogen Diffusion and Maximum

Principal Strain Distribution of FA 186 at Step 1. 
FA $186, \mathrm{~K}_{\mathrm{I}}=36.9 \mathrm{MPa} \sqrt{ } \mathrm{m}$
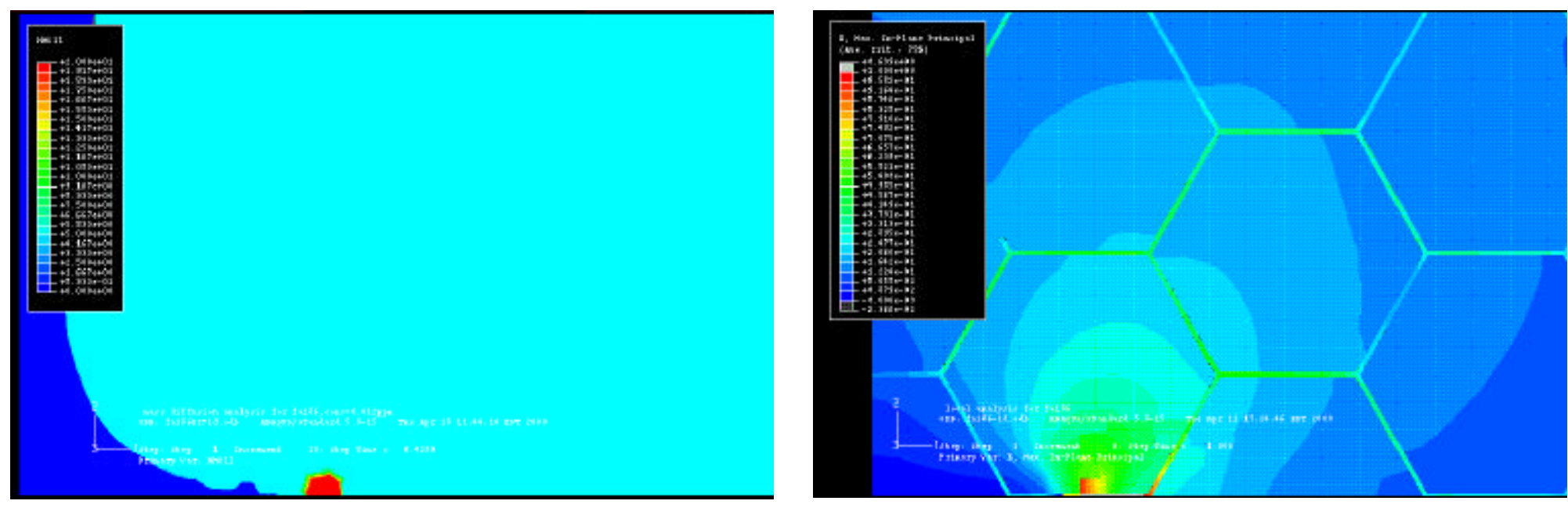

Hydrogen diffusion zone, step 1

$0.2 \mathrm{~mm}$

Maximum principal strain distribution, step 1
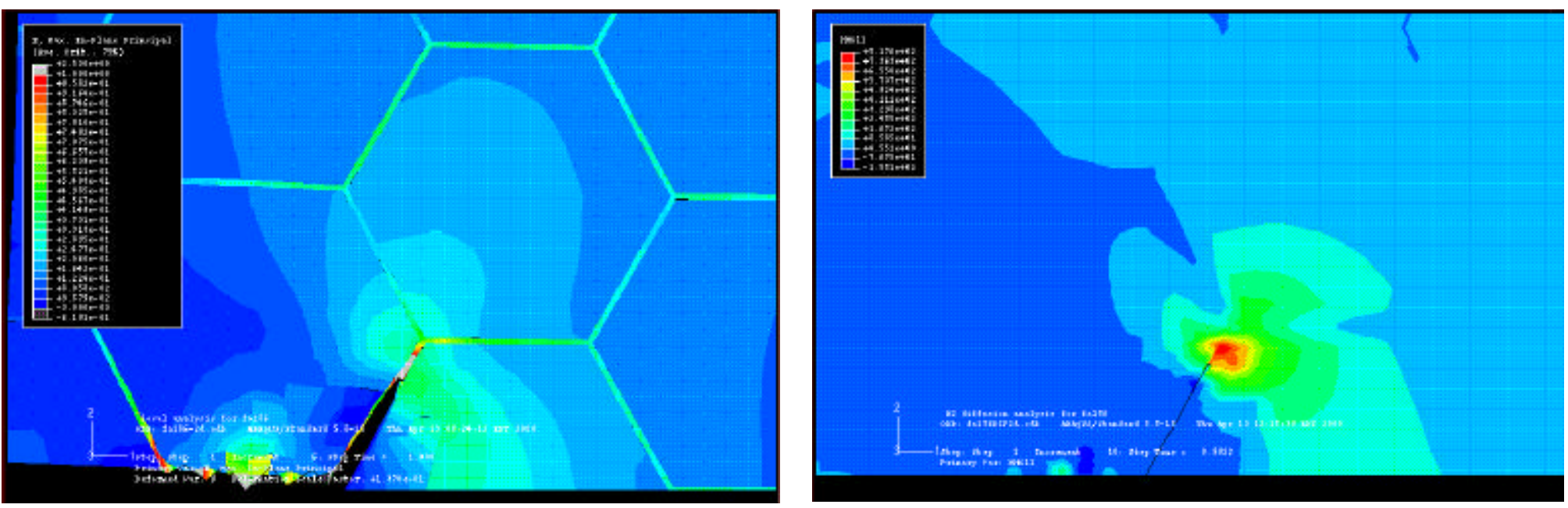

Maximum principal strain distribution after step 1,crack growth

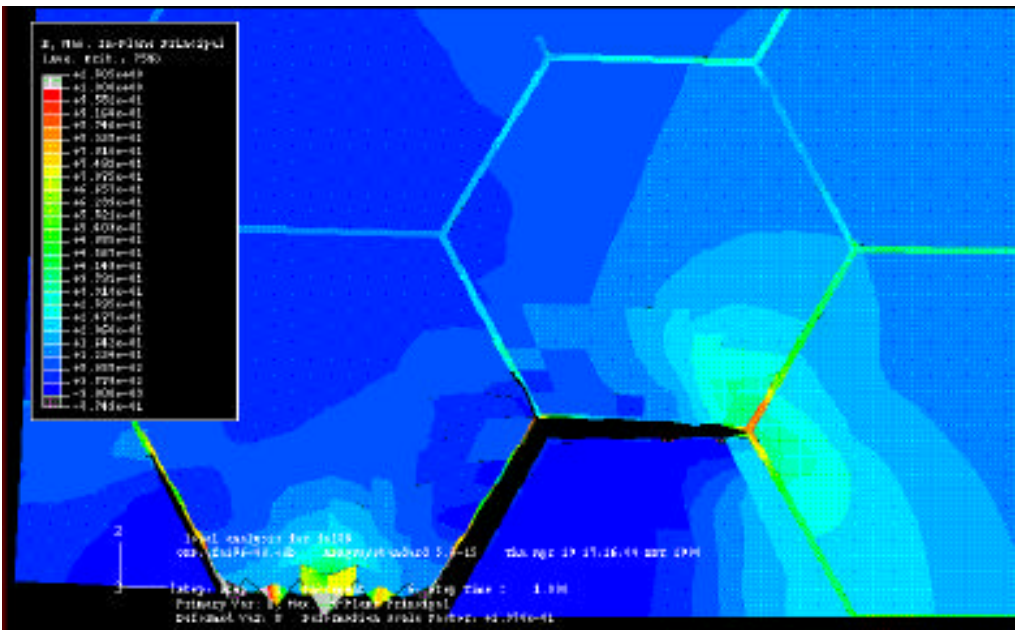

Maximum principal strain distribution step 2,crack growth

Hydrogen diffusion zone, step 2

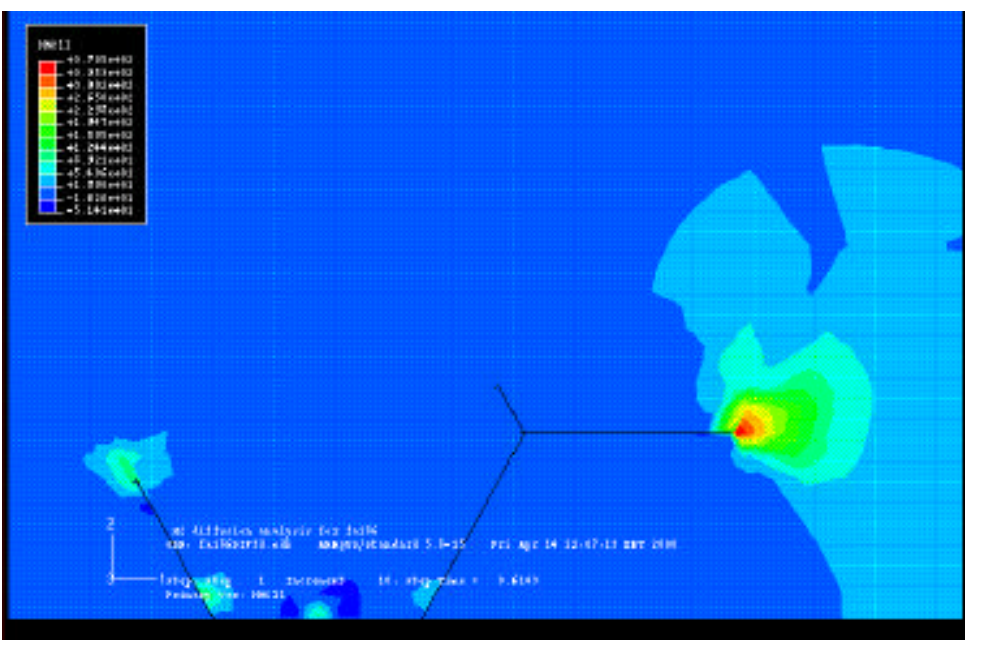

Hydrogen diffusion zone, step3

Fig. 9 Near Crack Tip Hydrogen Diffusion and Maximum Principal Strain Distribution of FA 186 at Higher Applied $K_{I}$ Value. 


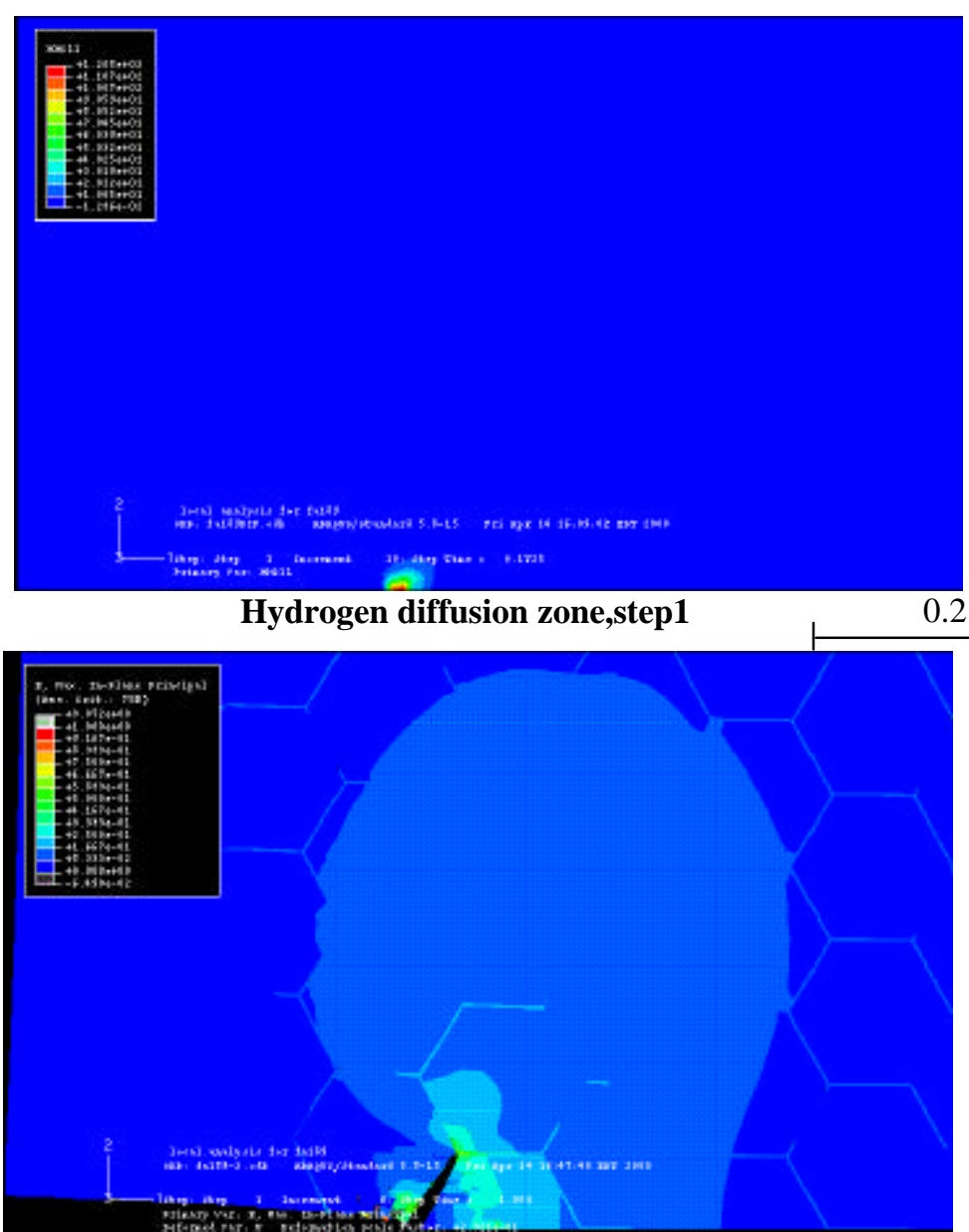

Maximum principal strain distribution, step 1,crack growth

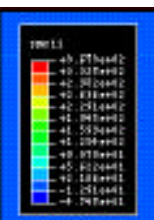

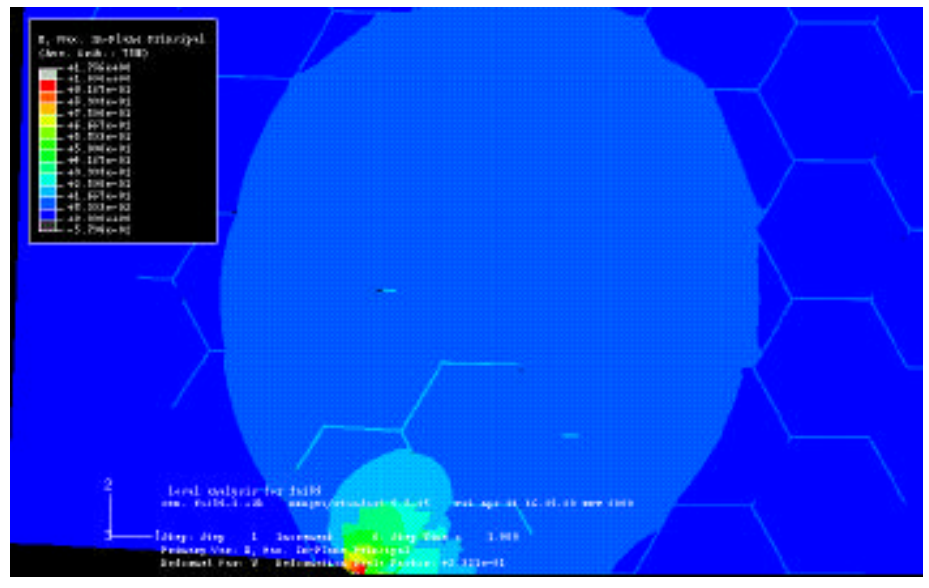

Maximum principal strain distribution, step 1

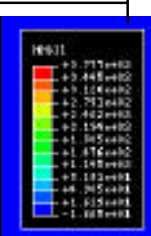

Inat mathet Ge tals

Hydrogen diffusion zone, step 2

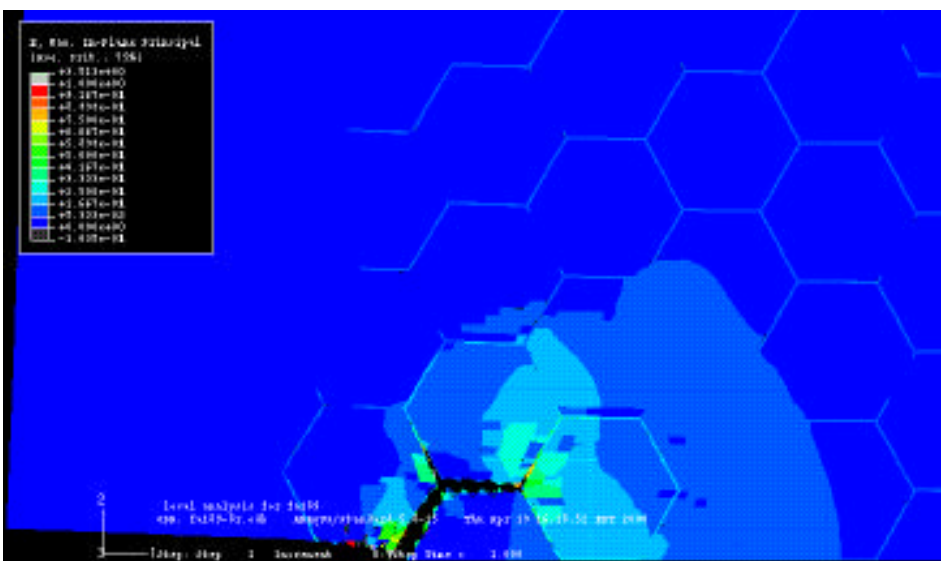

Maximum principal strain distribution, step 4, crack growth

\section{Hydrogen diffusion zone, step 4}

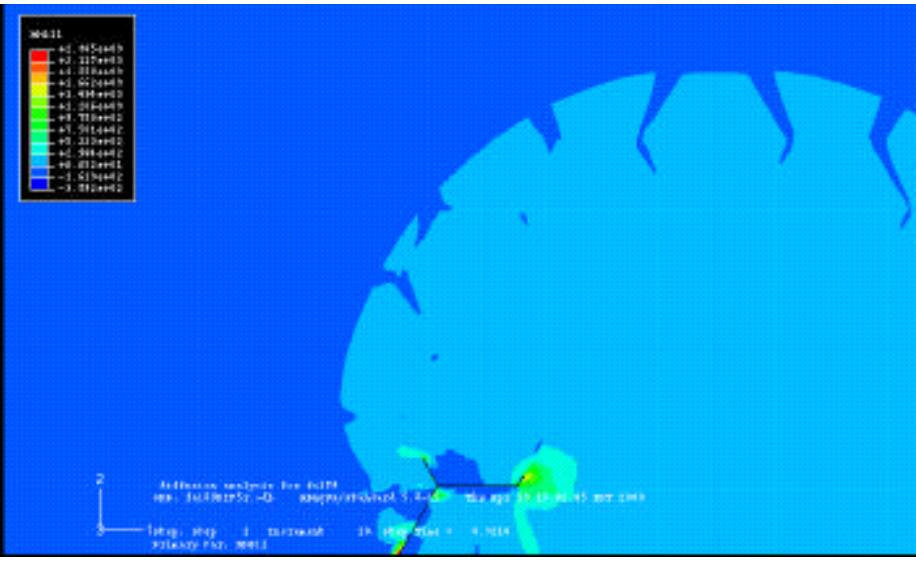

Hydrogen diffusion zone, step 5

Fig. 10 Near Crack Tip Hydrogen Diffusion and Maximum Principal Strain Distribution of FA 189. 